Article

\title{
Measuring Trust in Business Relations between Tourist Facilities on One Thematic Touristic Route
}

\author{
Adam R. Szromek (D) and Mateusz Naramski *(D) \\ Department of Organization and Management, Institute of Economy and Informatics, Silesian University of \\ Technology, Akademicka 2A, 44-100 Gliwice, Poland \\ * Correspondence: Mateusz.Naramski@polsl.pl; Tel.: +48-32-277-73-36
}

Received: 20 May 2019; Accepted: 17 July 2019; Published: 19 July 2019

\begin{abstract}
The aim of this article was to identify features and attributes of tourist facilities that affect trust among them and allows estimating the level of trust among any given site on a touristic route. The level of trust can be a key feature that affects the capability of tourist facilities to create and enter complex relations. It is also crucial for planning their future and sustainability. Therefore, measuring trust between tourist facilities plays a major role in the management of inter-organizational relations. The authors used statistical methods in order to identify features that influence the level of inter-organizational trust between these kinds of facilities. The analyzed data comes from research that was conducted in 2017 and describes 42 tourist facilities that operate within the Industrial Monuments Route (IMR) - a Polish route in the region of Silesia. A strong linear correlation was found between variables that described efficiency of communication and trust level. The Classification and Regression Trees (C\&RTs) method was used to identify features of tourist facilities that determine the efficiency of communication among them. Afterwards, the obtained data was used to create a multiple regression model that allowed estimating the level of trust between any given site on the route, identifying at the same time that features like communication efficiency, proximity and some institutional similarities have the greatest impact among tourist sites with regard to inter-organizational trust.
\end{abstract}

Keywords: inter-organizational trust; efficiency of communication; thematic tourist routes

\section{Introduction}

Market changes that took place in the second half of the 20th century [1,2] have left behind old technology, artifacts from the past, traditions and buildings that have lost their original function in post-industrial regions. Presently, they constitute an element of cultural heritage [3]. This heritage allows the use of tourism as a tool for restructuring the region and stimulating its economic development [4,5]. The sustainable development of tourism, based on the cooperation of stakeholders, is a source of benefits for the local communities, improves the quality of their life, as well as stimulating further tourist activity [6]. Moreover, actions supporting economic activity based on heritage do not merely play a commercial role but are also an important element of sustainable cultural development [7]. In this sense, tourism as a commercial activity allows the preserving and protecting heritage from dying out and degrading over time, utilizing the cultural heritage of the region as a value offered to clients. Quite often, responsibility for preserving heritage rests, among others, on the state and self-governments, making them stakeholders in the process of sustainable cultural development $[8,9]$. However, public funds are always limited and do not allow the protection of heritage to the extent possible by activating the tourist function.

Post-industrial tourist sites are basic units on which tourist traffic in post-industrial regions is based. Similar to all other forms of tourism and other branches of the economy, entities conducting tourist activity seek sources of competitive advantage and opportunities for improving the quality 
of their products. This allows ensuring survival in the conditions of ever-increasing competitiveness and market fluctuations. The effect is that an increasing number of organizations that conduct business based on servicing tourist traffic start to cooperate with each other and look for increasingly sophisticated forms of cooperation [10]. From the perspective of sustainable development, this process is all the more important since, as a result, facilities that base their activity on values resulting from cultural heritage preserve their ability to compete with other offers that emerge based on synthetic values currently created in line with the general idea of attracting tourists (e.g., amusement parks, water parks, etc.). It must be noted here that, although tourism based on cultural heritage is often perceived as a source of local economic growth, creating jobs and means for protecting heritage, it can result in degradation of the environment and heritage if it is not managed in a sustainable way [11]. Therefore, the cooperation of post-industrial tourist sites is important not only from a commercial point of view, but-if managed in a socially responsible manner-it will contribute to sustainable development. This is especially important for countries from the former Eastern bloc like Poland, where the development of nature and heritage protection has been delayed or even ignored for decades in comparison to other European countries [12]. However, since the transformation to free-market economy (1989), this aspect started to continuously improve. This can also be observed in the case of the Silesian Voievodship, which was the main coal basin in Poland and was industrialized at the end of the 18th century during the Prussian Partition. With the end of the industrial era, a vast amount of former industrial facilities, areas and artifacts where left to be forgotten and decay. However, those relics also represent the heritage of the region, and tourism has proven to be an effective means to preserve it. The current problem of rapidly developing industrial tourism is to find a balance and focus on sustainable development in order to prevent degradation of the environment and heritage mentioned above.

Trust between the cooperating parties is necessary, since it shapes the ability of an enterprise to establish and maintain relationships that are decisive for the relational capital of the enterprise [13]; this capital, if managed effectively, may act as a source of numerous benefits, including creating and strengthening a favorable image of the enterprise and obtaining approval of the organizations' surroundings for its business activities, increasing the effectiveness of acquiring and creating unique resources, as well as building the foundations of goodwill.

However, trust is a concept that is difficult to measure and compare directly without previously getting to know the organization and investigating or observing its internal environment. Developing a method that enables identifying the level of trust between the selected units, based on their characteristics and actions taken, would enable the quick and effective planning of relations and forms of cooperation between organizations in tourist entities, associated on a specific tourist route. Hence, the aim of this paper is to identify the features and attributes of post-industrial tourism entities that operate on a theme route, and have influence on the level of inter-organizational trust and allow the estimation of the level of trust. In other words, the main goal of the study is to find an answer to the following research question: Is there a set of features of touristic organizations operating within a route that can be used to evaluate the level of trust between them? An answer to this question would be a contribution both to the issue of inter-organizational trust and its measurement, as well as to the field of inter-organizational cooperation, and specifically within tourist sites and tourist routes. It would give a better insight into the processes of establishing trust and an understanding of features that affect the level of trust. Having those features identified would also further improve the exploration of this phenomenon, as well as organizational planning, since it would only require the measurement of those features and then applying them to an already established model. In order to answer this question, first, we reviewed the approaches to the issue of defining trust, its components and measurements found in literature. Then, those findings were incorporated into the development of a research questionnaire that was used to conduct structured expert interviews with the managers of industrial heritage tourist sites. The obtained data pertains to the level of trust between selected sites, as well as to various features of each tourist facility. The application of statistical methods shows whether there is any 
statistically significant dependency between those features and trust levels, providing an answer to the research question.

\section{Inter-Organizational Trust}

The concept of inter-organizational trust as a feature influencing cooperation between organizations already emerged in the literature of the subject in the past century but only gained the particular attention of scientists in the early 20th century [14]. From the point of view of sociology, trust is the foundation of social life, without which social life would not be possible in the form that is considered the norm [15]. This is due to the fact that trust occurs in all aspects of social life and plays an important role within them. Trust also allows the building of social capital. As F. Fukuyama [16] points out, social capital, understood as an ability of interpersonal cooperation in a group and an organization, for the purpose of achieving common goals, has a significant impact on the scale of economic institutions and their viability. The same author interprets trust as an acceptance of moral standards of a given society and adopting features such as loyalty, reliability and fairness. Moreover, there is a mechanism of mutual reinforcement between social trust and social networks [17]. Hence, to build long-term and stable inter-organizational relations, trust also has key importance.

When trust is created, cooperation can be built on it. In the case of tourism, the definition of D.J. Wood and B. Gray can be adopted [18], which says that cooperation is a voluntary undertaking of joint effort, in which autonomous stakeholders engage in an interactive process by using shared rules, norms and structures, in order to actively participate in, and influence, the development of tourism in a given region.

Despite the consensus between the majority of researchers, as to the research tools and methods, the subject of research itself (trust) is defined differently. In general, three approaches can be identified to understand trust: economic, sociological and intermediate. The classification of different dimensions of trust perceived in the literature of the subject, divided between the selected approaches, was made by the team of R. Seppänen [19]. Table 1 presents the dimensions of trust occurring in each of the three basic theoretical approaches.

Table 1. Dimensions of trust in main theoretical approaches.

\begin{tabular}{ccc}
\hline Economic Approaches & Intermediate Approach & Sociological/Psychological Approach \\
\hline Competence-based trust & Habitualization & Truth/Honesty \\
Calculative trust & Institutionalization & Confidence \\
Credibility & Integrity & Benevolence \\
Judgment & Dependability & Reliability \\
Responsibility & Likability \\
Contract trust & Goodwill \\
Predictability & Affect-based trust \\
& Cognition-based trust \\
& Faith \\
& Fairness \\
\hline
\end{tabular}

Source: [19].

Additionally, different researchers perceive the antecedents, consequences and dimensions or components of trust in various ways. Among the antecedents, R. Seppänen et al. [19] distinguished: intentionality, past behavior, relationship, social relationships and similarity. The consequences of trust that can be commonly found in literature include a reduction of risk, a reduction of costs, a deterrent of opportunistic behavior, the substitution of hierarchical governance, increased effectiveness and keeping business partners together. With regard to the dimensions or components of trust, the mentioned authors found that credibility, benevolence, goodwill, predictability, reciprocity, openness and confidence are the most frequent ones. Integrity can be classified both as an antecedent and component, and increased consequence can be a consequence and a component. There are also 
components of trust that can be antecedents and consequences. Those are: information sharing, cooperation, the continuity of relations or building relations, reputation, mutual satisfaction, a reduction of control, forbearance for opportunism, long-term goals, similar values, a level of communication and commitment. Finally, components of trust were also found that fall into all three dimensions: information sharing, knowledge, learning, predictability, lack of dependence, reliably, contracts, contractual trust, reduced use of contracts, expertise and competence.

On this basis, one can assume that trust is, at least partially, a bilateral process, and may be both a reason and an effect of joint effort [20]. The multitude of attitudes shaping inter-organizational trust shows how broad a concept trust is and how many features can affect it. In the perspective of entering into increasingly advanced forms of cooperation by tourist entities, it seems important to learn the level of trust of individual units towards their present and prospective partners.

\section{Measuring Trust}

K. Dalahaye Paine [21], of the Institute of Public Relations in Florida, made an attempt to quantify the level of trust. For this purpose, she prepared a group of questions with an assigned scale (e.g., from 1 to 9 for frequency of occurrence of a specific phenomenon). At the same time, she noted that, despite the existence of many methods and techniques of studying trust (e.g., focus groups, direct interviews, surveys, ethnographic studies, experiments, model building, etc.), there is no universal tool for measuring it. It is assumed that trust is a concept that is [21]:

- multi-level (between individual employees, the team, organization as a whole and between organizations);

- rooted in culture (has strong ties with standards, values and beliefs in the organizational culture);

- based on communication (is a product of dialog_sharing information, explaining the adopted decisions, showing openness);

- dynamic (constantly changes along with current events);

- multi-dimensional (trust consists of numerous features that are both cognitive, emotional and behavioral, such as competence, openness and honesty, dependability or reliability, integrity, concern for employees, control mutuality, identification, commitment and satisfaction).

As previously demonstrated, trust manifests itself in openness and willingness to share information. Knowledge is the productive use of information and constitutes one of the most important resources of an organization [22]. Therefore, it may be assumed that sharing knowledge is a larger expression of trust than sharing information alone. Five decisive features have been identified for willingness to share information [23]:

- Belonging to a network-units that are members of a specific society or network are more willing to share knowledge and experience with the other group members, compared to the ones that are outside of it.

- Proximity (in the sense of location in space)—the shorter the distance between companies and employees, the more intense the contacts established between them.

- Institutional similarity-entities with a similar organization are more willing to mutually exchange knowledge.

- Similar knowledge resources-as a result of the relative absorption ability phenomenon, communication and the exchange of knowledge between entities with similar knowledge in the given sphere is much easier.

- Relational similarity—similar experiences and historical background of people and enterprises increase their willingness for the mutual exchange of knowledge.

Proximity has been listed among the features that are decisive in the willingness to share knowledge and build trust. In strategic management, this proximity is defined as a similarity of properties, features 
and attributes of an organization and is used as a variable describing process of cooperation [24]. The level of proximity between organizations affects the benefits resulting from cooperation, increasing the likelihood of their occurrence (stronger and more lasting ties in a network, accelerated development of knowledge, increase of effectiveness in the network and entities creating it), as well as reducing the chance for the occurrence of threats (e.g., eliminating communication barriers and reducing opportunist behaviors) [25]. Many authors [25-27] treat proximity like the previously mentioned features affecting the willingness to share knowledge, identifying five of its dimensions: organizational, geographic, institutional, cognitive and social [26]. P. Klimas and S. Twaróg identified the bases for proximity in all of the mentioned dimensions; these include [28] (1) space and time distance between the entities (geographical dimension); (2) interpersonal relations connecting employees (social dimension); (3) institutional similarity of belonging to the same network (organizational dimension); (4) institutional surrounding, along with cultural surrounding (institutional dimension) and (5) similarity of cognitive processes, homogeneity and heterogeneity of possessed knowledge bases, and similarity in mental models (cognitive dimension). Along with the development and duration of networks, trust may grow in individual dimensions. Cooperation bringing partners together in the interpersonal dimension (social proximity is built). The exchange of knowledge and technology contributes to an increase in cognitive proximity, and sharing organizational culture is reflected in organizational proximity. Institutional proximity, on the other hand, will be the effect of a joint effort within the same institutional surrounding and the fulfillment of the same formal and informal aspects when conducting joint effort. Using proximity to tighten inter-organizational bonds and its development in all dimensions is the effective method for fostering the achievement of cooperation goals and building inter-organizational trust [29].

As previously mentioned, trust is one of the key aspects that are decisive for the establishment of cooperation between partners. Measuring trust is not an easy task; a detailed overview of the literature on this subject was made by a team lead by R. Seppänen [19]. The authors of this publication show that the definite majority of scientists from all over the world use e-mail surveys or conduct direct interviews when estimating inter-organizational trust. Questions used can be answered by choosing a value from a multi-level scale, allowing respondents to assess the general level of trust towards a specific entity or a certain aspect affecting trust. The questions are usually directed at a single representative of the organization (usually a senior manager), and the obtained quantitative data are subject to exploratory or confirmatory feature analysis.

When measuring cooperation, forms are often used, in which respondents, using Likert scales, assess a given behavior (agreeing or disagreeing with it) that may point to cooperation with other entities [30]. In such a case, these may concern the assessment of the strengths of bond with the other entity, mutual satisfaction, competing for resources, frequency of occurrence of tensions and conflicts, attempts at gaining competitive advantage, frequency and regularity of communication, sharing problems, etc. [30].

As shown, trust is a broad concept, understood by researchers in various ways, depending on the practiced discipline of science, the assumed definition and the studied phenomenon. This may hinder conducting studies in this scope, since the concept, although well understood in informal speech, may have a slightly different meaning among the respondents of surveys, participants of interviews or even experts.

In view of the presented results, it may be concluded that inter-organizational trust is one of the key elements of cooperation, while effective communication, the exchange of knowledge and experiences, has a significant impact on its degree. To identify features affecting the level of inter-organizational trust between tourist sites operating on the same route, it is necessary to study the characteristics of each site and determine the relations between them. An awareness of those features should reduce the knowledge gap about trust establishment in the case of such specific organizations like tourist enterprises that oftentimes differ significantly from other businesses, providing a better insight into what features matter the most in their case, considering the trust levels between them. Empirical 
research conducted in this matter is also a contribution to the issue of measuring trust between multiple entities functioning in a larger construct (in this case a route), in a quantitative form that allows direct comparison between various cases, and could be adapted with minor changes to other cases.

\section{Materials and Methods}

The research material used in the study was gathered in the second half of 2017. During the study, the method of structured expert interviews was used. For this purpose, a questionnaire was prepared that contained over 70 questions:

- open-ended questions - to identify their attitude towards networking;

- assessment requests by using a classification scale - to assess level of trust and communication effectiveness between selected pairs of sites, as well as to assess thewillingness and readiness to undertake given forms of cooperation within tourist sites and to perform selected self-assessments;

- yes/no questions, and multiple-choice questions-designed to point out desired cooperation partners and roles a site could take within a cooperation network.

The structured interview form was used in order to maintain the same structure for each interview and to obtain comparable data. The results presented in this paper were the first stage of a main study. At this stage, we focused on the quantitative data from the interviews that characterize the tourist sites, as well as the level of trust and communication effectiveness between them. This data comes from classification-scale questions only, where we used a 1 to 10 scale, as suggested by K. Dalahaye Paine [21] in her paper dedicated to measuring trust. The data from the other types of questions (open-ended questions and yes/no questions, etc.) alongside the quantitative questions presented here were used in the second stage of the main study, where we used the data to design an inter-organizational network for tourist sites [31].

The interviews were made with the representatives of all (42) sites situated along the Industrial Monuments Route (IMR). Therefore, the research was comprehensive (it involved all sites). The rationale behind selecting this route is that it is the only route in Central Europe belonging to the European Route of Industrial Heritage (ERIH). It is also the largest tourist post-industrial route in Poland (in terms of the number of associated sites, which, at the time of the conducted research, was 42). The other routes in Poland comprise less than half of the IMR sites. They are also not as diverse in terms of the presented theme (they bring together sites of a single type, e.g., lighthouses, railway buildings, etc.) as the IMR, which includes sites such as mines, museums, factories, etc. Moreover, the IMR is characterized by a high level of development and formalization. The exact list of sites and the IMR map is presented in Figure 1. In the interviews, responses were given by people with senior managerial roles.

The questions were aimed at characterizing the studied entities in terms of: number of tourists visiting the site and distribution of tourist traffic in the year, forms of ownership, number of employees, number of years of activity on the tourist market, type of site (e.g., museum, former production plant, underground tourism route, etc.).

Furthermore, the respondents were requested to use a scale of 1 to 10 (the greater the value, the better the assessment) to assess the effectiveness of communication and level of trust towards nine other entities operating within the IMR (three with the largest and three with the smallest geographical proximity, as well as three with the largest institutional proximity). Applying the same scale, the experts also assessed readiness to undertake different forms of cooperation (sharing experiences from different kinds of conducted activity, creating joint products with other members of the IMR, joint promotional effort, etc.).

The experts also assessed aspects such as the subjectively felt impact of the represented site on the development of the IMR, strength of the site compared to other units within the IMR, difficulty in meeting expectations posed by the managers of the route, balance of profit to loss resulting from belonging to the IMR, and degree of materialization of the expectations they had when joining the IMR, 
as well as the attitude to creating a network structure along the route. The mentioned aspects were also evaluated using a scale of 1 to 10, where 1 expressed an extremely negative, and 10 expressed an extremely positive attitude towards a given issue, while 5 expressed neutrality in a given aspect.

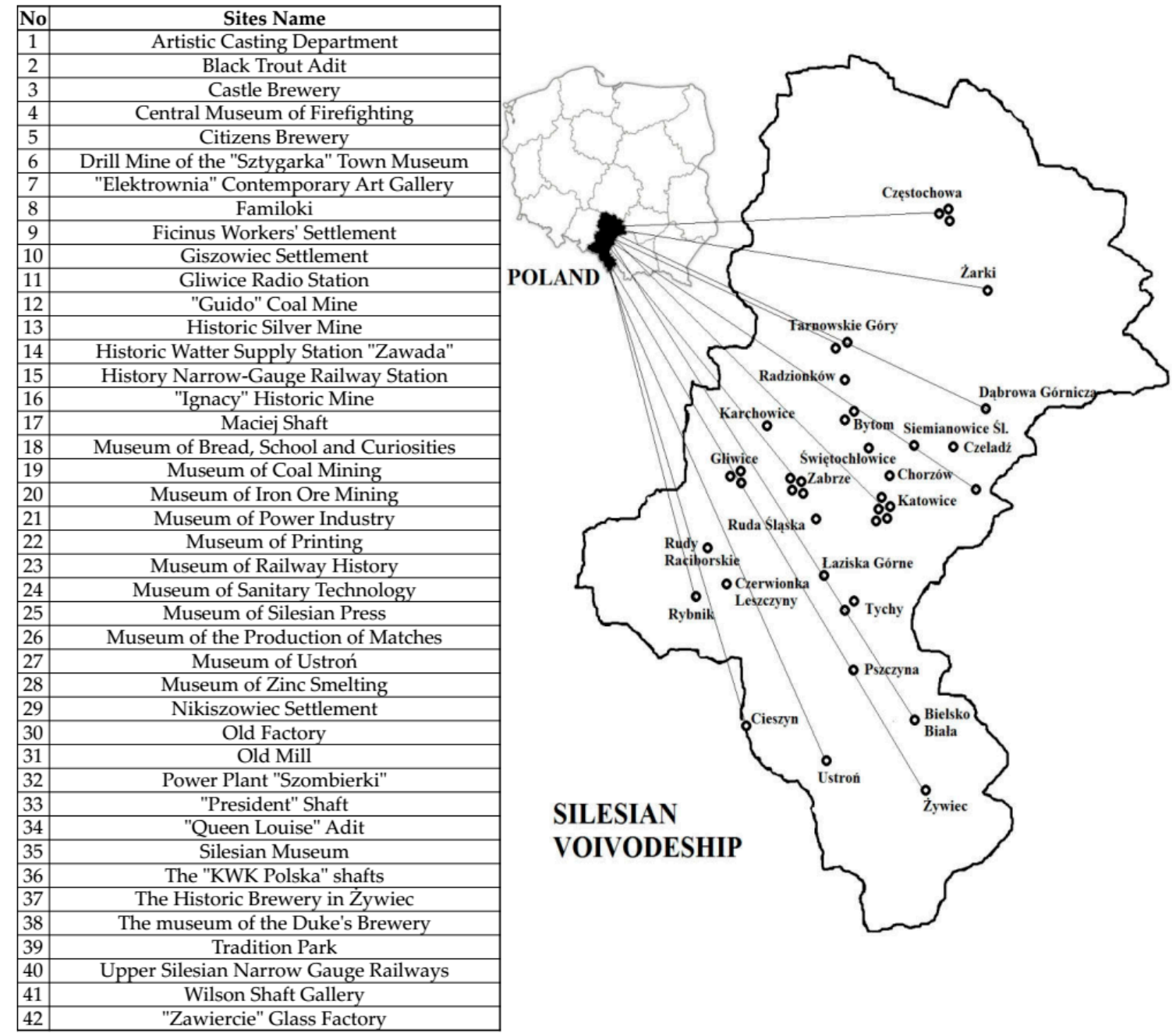

Figure 1. Industrial Monuments Route (IMR) sites on the map of the Silesian Voivodeship. (Source: [32]).

The data presented in this paper contained variables that characterized all 42 sites on the IMR (self-assessment of sites concerning their position on the IMR, tendency and readiness to participate in selected forms of cooperation). The research material was subjected to statistical analysis, determining average values, standard deviations, the maximum and minimum value, coefficient of variation and quartiles for each of the scores. When checking whether there are significant statistical co-dependencies between the variables, the Pearson's linear correlation coefficient was calculated, and its strength was interpreted in accordance with the criteria assumed in the literature of the subject.

The gathered data also contained a sample of 215 assessments of level of trust and communication efficiency between pairs of the IMR sites (from the 861 non-repetitive pair combinations). This data alongside the previously mentioned characteristic of the IMR sites was subject to further analysis.

First the Classification and Regression Trees [33,34] (C\&RTs) method was used to identify variables describing tourist sites, which allowed assessing the effectiveness of communication between any given pair of entities. This method differs from the frequently used approaches in tourist research when testing hypotheses and analyzing data [35] that is not overly complex and concerns a large amount of data [36]. The created model was used for estimating the effectiveness of communication 
for all possible combinations of pairs of tourist sites (in the study, each expert assessed this parameter for 9 of the 41 remaining sites).

Afterwards the obtained estimations were applied, together with the other variables describing the studied entities, as a parameter enabling the estimation of the level of inter-organizational trust between any given pair of sites. To this end, the multiple regression model was used. As a result, features and attributes of the post-industrial tourist sites were identified, which impact the level of inter-organizational trust between them.

The created regression model was tested for autocorrelation using the Durbin-Watson test. The Shapiro-Wilk test was conducted in order to test the residual distribution. We also performed an analysis of variation (ANOVA) for the regression.

\section{Results}

In the initial phase of the conducted expert interviews, a characterization of the evaluated sites was made. Within the IMR, $63.41 \%$ of the sites are public entities, while $21.95 \%$ are private. The remaining $14.63 \%$ are non-governmental organizations. In terms of the number of tourists visiting the IMR sites, the average value was $19,473 \pm 21,260$. The most frequently $(99,421)$ visited site is the Guido Mine; the annual number of visitors in this site many times higher than in the site with the smallest attendance (730)—-the Citizens' Brewery. The average number of people employed in a post-industrial tourist site in the Silesian Voivodeship is 13 people, while the standard deviation for this feature is 19 people; hence, the difference in employment varies notably between sites. The average distance between these sites within the IMR is $58.74 \pm 48.03 \mathrm{~km}$. The largest distance between the sites is $164 \mathrm{~km}$, and the smallest is $1.1 \mathrm{~km}$.

Furthermore, using a scale of 1 to 10, the experts made a self-assessment of the represented sites. They assessed the subjectively perceived strength of the represented site, compared to other participants of the route, the impact of the site on the development of the IMR, the level of materialization of expectations they had when joining the IMR, the relation between benefits and difficulties resulting from membership in the IMR, their attitude to the process of the networking of the IMR and the difficulties in meeting the expectations posed by the IMR towards the site. Table 2 presents the descriptive parameters of the obtained scores.

Table 2. Self-assessment of the IMR tourist sites.

\begin{tabular}{|c|c|c|c|c|c|c|c|c|}
\hline Variable & Average & Standard Deviation & $\mathrm{Q}_{1}$ & $\mathrm{Q}_{2}$ & $\mathrm{Q}_{3}$ & Min & Max & $\mathrm{CV}$ \\
\hline Strength & 6.41 & 2.02 & 5 & 5 & 8 & 4 & 10 & 31.56 \\
\hline Influence on the IMR & 5.34 & 2.14 & 5 & 5 & 6 & 1 & 10 & 40.07 \\
\hline Expectations met by the IMR & 7.3 & 2.39 & 6 & 7 & 10 & 1 & 10 & 32.76 \\
\hline Pros/cons of being on the IMR & 8.13 & 2.06 & 7 & 8.5 & 10 & 1 & 10 & 25.28 \\
\hline Networking tendency & 7.92 & 1.95 & 7 & 8 & 10 & 4 & 10 & 24.63 \\
\hline Difficulty in meeting the IMR expectations & 7.38 & 2.43 & 5.5 & 8 & 10 & 2 & 10 & 32.88 \\
\hline
\end{tabular}

Source: Authors' research. $\mathrm{Q}_{1}, \mathrm{Q}_{2}, \mathrm{Q}_{3}-1$ st, 2nd and 3rd quartile, Min-minimal value, Max-maximal value, $\mathrm{CV}-$ coefficient of variation.

Another stage of the conducted interviews was the assessment of readiness in the assessed entities to undertake joint effort with the other members of the route, requiring high trust and effective communication. Again, using a scale of 1 to 10, the experts evaluated 19 potential forms of cooperation with other sites on the route (giving the lowest score to the form they were not interested in, and the highest to the one they were ready to implement as soon as possible). Table 3 shows the obtained results.

The last part of the interview directly concerned the effectiveness of communication and level of trust between the IMR sites. Each expert was requested to assess the two aspects, as compared to the nine other sites on the route, using the previously used scale of 1 to 10 . Three of them were situated in the closest geographical proximity (The difference corresponded to the shortest distance to be covered between two sites, obtained using the Google Maps service [37]. This distance was thus not a representation of the Euclidean distance between a pair of sites in a straight or urban line 
(Manhattan), but the shortest route to be covered by a car. This measure of distance was applied, since it better reflects the distance to be covered by the respondent, and this is the measure that reflects the notion of distance to the given site.), the same as in the case of the most distant, and the other three were sites with the greatest similarity to the unit represented by the expert. (In this case, the similarity was estimated based on the categorization of sites according to their kind, theme and the past product or service that the given site offered before it became a monument. Additionally, tags occurring on the website of the route [38], used for describing the studied sites, were taken into account. The greater the compatibility of those tags, the higher the similarity was evaluated.) The number of obtained assessments for the variable corresponding to the effectiveness of communication was 211 and for the level of trust, it was 214. The difference stems from the fact that not all experts assessed each of the nine sites in both of the aspects. Table 4 shows the obtained results, it contains both: (1) the overall assessment of trust level and effectiveness of communication between tourist sites, and (2) the results of those two variables within three individual groups of sites (nearest, furthest, most similar).

Comparing the assessed degrees of trust and effectiveness of communication between the individual groups, it was noted that significant statistical results exist between the average values $(p<0.05)$. In the case of assessing the effectiveness of communication, this was the case for the pairs: overall assessment and sites situated the furthest apart $(p=0.007)$, the nearest and the furthest sites $(p=0.001)$, as well as similar and the furthest sites $(p=0.030)$. However, for the average degrees of the level of trust, significant differences occurred for two pairs of variables: overall assessment of the level of trust and the level of trust in the furthest sites $(p=0.038)$ and between the nearest and the furthest sites $(p=0.003)$. The other differences in average assessments were statistically insignificant.

Table 3. Tendency and readiness to participate in given forms of cooperation in the IMR sites.

\begin{tabular}{|c|c|c|c|c|c|c|c|c|}
\hline Variable & Average & Standard Deviation & $\mathrm{Q}_{1}$ & $\mathrm{Q}_{2}$ & $\mathrm{Q}_{3}$ & Min & Max & $\mathrm{CV}$ \\
\hline Organizing joint events & 7.77 & 2.4 & 10 & 8 & 7 & 1 & 10 & 30.89 \\
\hline $\begin{array}{l}\text { Establishing consistent e-mail } \\
\text { communication }\end{array}$ & 7.92 & 2.95 & 10 & 10 & 6.5 & 1 & 10 & 37.27 \\
\hline Creating a unit for network cooperation & 5.88 & 3.46 & 10 & 7 & 2 & 1 & 10 & 58.92 \\
\hline Assigning a delegate for collaboration & 7.66 & 3.11 & 10 & 9 & 6 & 1 & 10 & 40.58 \\
\hline Creating shared product with near sites & 8.33 & 2.17 & 10 & 9 & 8 & 1 & 10 & 26.02 \\
\hline $\begin{array}{l}\text { Creating shared product with similar } \\
\text { sites }\end{array}$ & 7.56 & 2.55 & 10 & 8 & 6 & 1 & 10 & 33.75 \\
\hline Organizing joint events & 7.22 & 2.56 & 10 & 8 & 5 & 1 & 10 & 35.40 \\
\hline \multicolumn{9}{|l|}{$\begin{array}{l}\text { Readiness to include promotional contents } \\
\text { concerning a partner: }\end{array}$} \\
\hline In printed materials & 7.89 & 2.76 & 10 & 8 & 8 & 1 & 10 & 34.94 \\
\hline On the website & 7.18 & 3.22 & 10 & 8 & 7 & 1 & 10 & 44.84 \\
\hline In social media & 7.64 & 3.00 & 10 & 8 & 8 & 1 & 10 & 39.32 \\
\hline On tickets & 6.44 & 3.44 & 10 & 8 & 2 & 1 & 10 & 53.40 \\
\hline In the guides' presentation & 8.32 & 1.97 & 10 & 8 & 8 & 1 & 10 & 23.61 \\
\hline \multicolumn{9}{|l|}{ Tendency to share experiences regarding: } \\
\hline Work organization & 6.69 & 3.13 & 9 & 8 & 5 & 1 & 10 & 46.77 \\
\hline The reservation system & 6.53 & 3.19 & 8 & 8 & 5 & 1 & 10 & 48.90 \\
\hline Promotional activities & 7.76 & 2.55 & 10 & 8 & 8 & 1 & 10 & 32.87 \\
\hline Raising funds & 6.83 & 3.44 & 10 & 8 & 4.5 & 1 & 10 & 50.39 \\
\hline Tenders & 5.84 & 3.83 & 9 & 8 & 1 & 1 & 10 & 65.52 \\
\hline Investments & 5.60 & 3.64 & 9 & 6 & 1 & 1 & 10 & 65.00 \\
\hline Sale of the product & 7.13 & 3.21 & 10 & 8 & 5.5 & 1 & 10 & 45.02 \\
\hline
\end{tabular}

Source: Authors' research.

A strong positive linear correlation was noted $\left(r_{x y}=0.891, p<0.05\right)$ between the level of trust and the effectiveness of communication. This means that the effectiveness of communication may be a very important parameter when defining the level of inter-organizational trust. Moreover, a weak negative linear correlation was identified between the distance dividing the two sites and the evaluation of the effectiveness of communication $\left(r_{\mathrm{xy}}=0.31, p<0.05\right)$ and the level of trust $\left(r_{\mathrm{xy}}=0.32, p<0.05\right)$. 
Table 4. The evaluation of communication efficiency and level of trust among the IMR sites.

\begin{tabular}{ccccccccc}
\hline Variable & Average & Standard Deviation & $\mathbf{Q}_{1}$ & $\mathbf{Q}_{2}$ & $\mathbf{Q}_{3}$ & Min & Max & CV \\
\hline Overall efficiency of communication & 6.29 & 3.25 & 4 & 7 & 10 & 0 & 10 & 51.61 \\
\hline Efficiency of communication in groups of: & & & & & & & & \\
• nearest sites & 6.97 & 2.94 & 5 & 8 & 10 & 0 & 10 & 42.2 \\
• furthest sites & 4.81 & 3.29 & 1 & 5 & 8 & 1 & 10 & 68.46 \\
• similar sites & 6.24 & 3.37 & 3 & 7 & 10 & 1 & 10 & 54.01 \\
Overall level of trust & 6.74 & 2.76 & 5 & 7 & 9 & 0 & 10 & 41 \\
\hline Level of trust in groups of: & & & & & & & & \\
• nearest sites & 7.29 & 2.72 & 5 & 8 & 10 & 0 & 10 & 37.29 \\
• furthest sites & 5.8 & 2.68 & 5 & 5 & 8 & 1 & 10 & 46.29 \\
• similar sites & 6.58 & 2.73 & 5 & 6 & 9 & 1 & 10 & 41.49 \\
\hline
\end{tabular}

Source: Authors' research.

The evaluation of the effectiveness of communication and the level of trust between the post-industrial tourist sites were also compared to the absolute values from the difference of the other assessments of experts (assessment of a given aspect, made by an expert assessing the level of trust and the effectiveness of communication, minus the assessment of the same aspect made by an expert in the assessed site). Nine statistically significant linear dependencies between the level of communication and the mentioned features and eight between the level of trust and the mentioned features were identified. All of the calculated coefficients fall within the interval of $0.1<\left|r_{x y}\right|<0.4$. Therefore, each of these correlations are weak or very weak, but statistically significant $(p<0.05$ for each of these cases); their values are presented in Table 5.

Table 5. Pearson's correlation coefficient between the assessment of communication effectiveness and level of trust between the IMR sites.

\begin{tabular}{|c|c|c|}
\hline Variable $^{3}$ & $r_{\mathrm{xy}}{ }^{1}$ & $\begin{array}{c}p \\
\text { Statistical Significance }\end{array}$ \\
\hline \multicolumn{3}{|l|}{ Communication effectiveness } \\
\hline Willingness to include partner's offer in social media & -0.184 & 0.011 \\
\hline Number of employees & 0.246 & 0.002 \\
\hline Readiness to organize joint events with others & -0.163 & 0.029 \\
\hline Willingness to establish permanent e-mail communication & -0.196 & 0.023 \\
\hline Readiness to create shared products with similar sites & -0.228 & 0.002 \\
\hline Tendency to share experience regarding raising funds & -0.193 & 0.011 \\
\hline The influence of a site to shape the IMR & 0.205 & 0.003 \\
\hline Networking tendency & -0.239 & 0.001 \\
\hline The level of difficulty of a site in meeting the IMR requirements & -0.198 & 0.005 \\
\hline \multicolumn{3}{|l|}{ Trust level } \\
\hline Willingness to include partner's offer in social media & -0.166 & 0.021 \\
\hline Number of employees & 0.201 & 0.012 \\
\hline Willingness to establish permanent e-mail communication & -0.181 & 0.034 \\
\hline Readiness to assigning a delegate for collaboration & -0.218 & 0.019 \\
\hline Readiness to create shared products with similar sites & -0.160 & 0.025 \\
\hline The influence of a site to shape the IMR & 0.168 & 0.014 \\
\hline Networking tendency & -0.225 & 0.001 \\
\hline The level of difficulty of a site in meeting the IMR requirements & -0.142 & 0.044 \\
\hline
\end{tabular}

For the majority of variables, the coefficient of linear correlation with the level of trust and effectiveness of communication was negative. This means that, to trust each other and hold effective communication, a consensus between the managers of the assessed sites in their views on cooperation must be present (the higher the similarity in assessments of the presented variables in the two sites, the higher the mutual trust and communication were assessed). The exceptions are: the difference in the number of employees and the difference in the assessment of the perceived impact of the sites on shaping of the IMR. This may mean that, in the assessed sites, greater trust is enjoyed by entities with a 
different scale of employment and, thus, size of the enterprise. Most probably, sites with a relatively large number of employees do not see a competitive threat in small enterprises, are more willing to establish communication and express greater trust towards them than towards the units with a similar scale of activity (towards which, despite cooperation within the route, strong competition for the client exists). The second of the positive correlations strengthens this assumption, since similar dependency in the assessments of the level of trust and the effectiveness of communication existed with a variable describing the perceived impact of the unit on the shaping of the IMR. The higher the difference in this respect between the two sites, the higher the level of trust and effectiveness of communication between these units. The impact of the unit on the shaping of the route largely depends on its size, expressed in the number of employees and number of tourists visiting the site throughout the year.

The conducted analysis allowed identifying the variables describing the institutional similarity which, in post-industrial tourist sites, impact the level of trust within the network and the effectiveness of communication.

The intention of the authors was to identify the features and attributes of tourist sites affecting the level of inter-organizational trust between the studied entities. Therefore, the next stage of the research was to create a statistical model enabling the assessment of the level of trust between any given pair of the IMR sites. Knowing that there is a strong correlation between the effectiveness of communication and the level of trust, an attempt was made to first estimate the effectiveness of communication between all the pairs of the IMR sites, and then use it as one of the variables (along with the other parameters describing the IMR sites) in a model estimating the level of trust in the most accurate way possible. The observations from expert interviews were used to verify the accuracy of predictions obtained using a model, by calculating the coefficient of determination and Pearson's linear correlation.

Many methods were tried in the search for the most accurate estimation of the level of communication between any given pair of sites (including non-linear estimation, general regression models, factor analysis, etc.), and then the obtained predicted values were compared with the observations in the studied samples, checking their degree of correlation. However, the use of conventional methods did not bring the expected effects. The coefficient of determination was small, the coefficient of linear correlation between the prediction and the observation did not exceed $r_{x y}=0.5$. Therefore, to accurately estimate the level of effectiveness of communication, the C\&RTs method was used. It allows assign a given observation to one of the determined classes, based on similarity with other observations of the same characteristics. In each of the determined classes, the values of the predicted variable are approximate to each other, and it is assumed that the prediction is equal to the value of the average estimated variable in a given class. The tool used (Statistica 12 Software) allows comparing many regression trees with each other (the more branches, the more accurate the prediction). The best of the obtained regression trees in the conducted analysis had 21 branched nodes and 22 final nodes. The comparison of the actual observations with the predicted values, obtained by using the C\&RTs method, showed a linear correlation at the level of $r_{\mathrm{xy}}=0.796$ - this was the highest obtained result compared to the other methods.

The applied classification tree was presented in Figure 2. The name of the variables used in every branching of the set of observations into two subsets can be read from the figure; they are located beneath the branching lines. On the right and left end of the branching, there is a value that the given variable had to have in order to define the subsequent division criterion and belonging to a specific subset. The final subsets, called the leaves, are not subject to further branching; it is assumed that the value of the dependent variable (effectiveness of communication) is equal to the value of the average indicated for the given subset. Every variable used during the classification was an absolute value from the difference in assessment of the given parameter in two sites, for which the effectiveness of communication was predicted, e.g., the third node (ID = 3) in the presented tree is split, based on the variable describing the attitude towards networking in two sites. If the absolute value from the difference in assessments was greater than 4.5 , another division would start from node ID = 27; otherwise, it would start from node 26 . The majority of variables deciding the selection of a given 
route of division concerned the observations assessed on a scale of 1 to 10 in two sites; the exceptions are: distance between the two sites, difference in years of activity and difference in the number of tourists served in a given year.

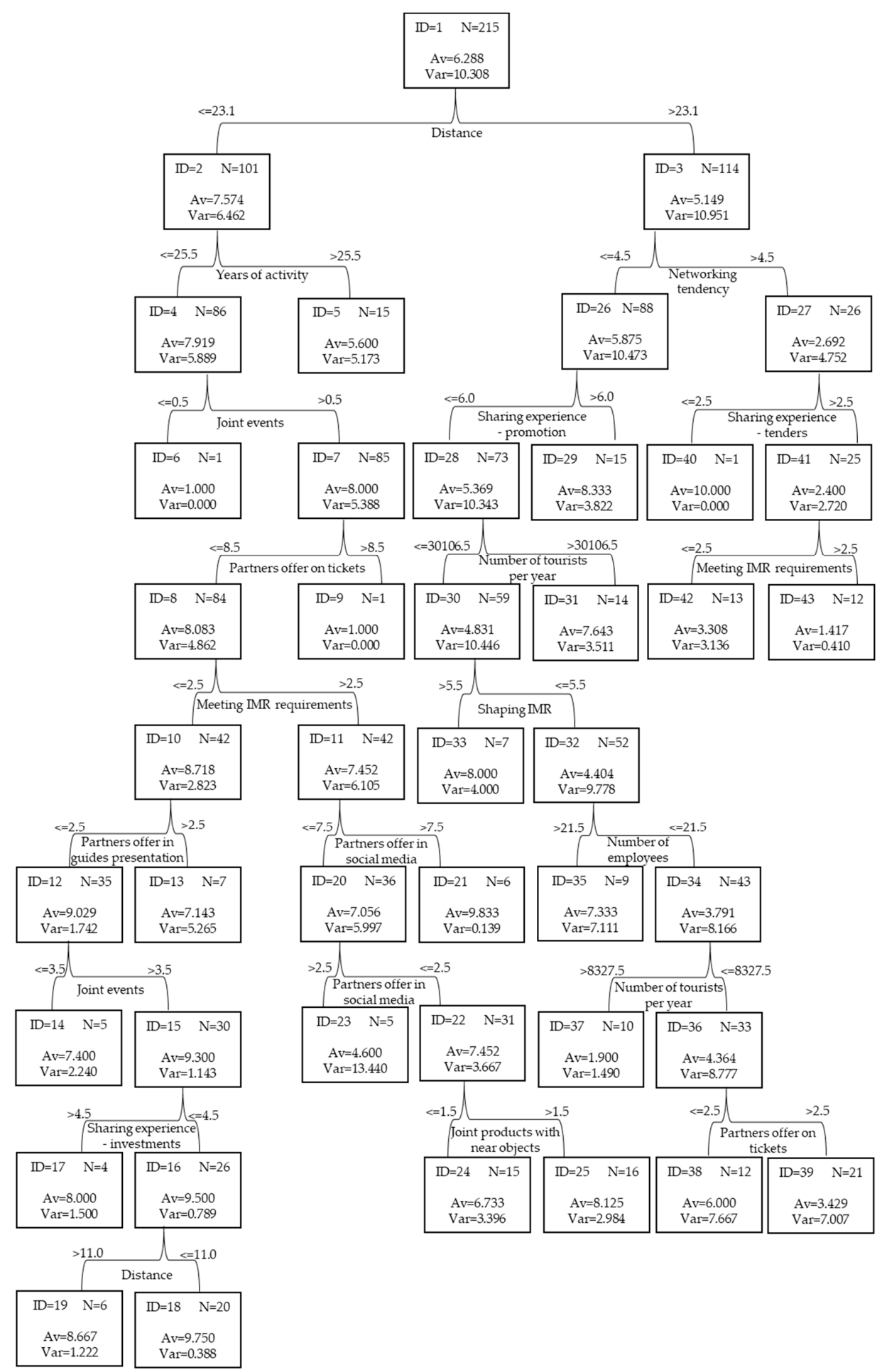

Figure 2. Classification tree used to estimate the efficiency of communication between the IMR sites, created using the Classification and Regression Trees (C\&RTs) method included in the STATISTICA12 software suite (Source: Authors' own work.). 
Based on the obtained classification tree, it is possible to identify the features of touristic sites from the IMR that have a significant influence on the effectiveness of communication between them. Those features are:

- $\quad$ The distance between two sites.

- The difference in the number of years between two objects functioning as a touristic site, tourists visiting a pair of sites in a year, and employees in two sites.

- The readiness in two sites to organize joint events and create a shared product with near sites.

- The networking tendency in two sites.

- The difference of influence a site feels that it has on shaping the IMR between a pair of sites.

- The difference in two sites on how the difficulty in meeting the IMR requirements is perceived.

- The readiness in a pair of sites to include partner's offers on tickets, in guide presentation (verbal advertising for partner sites during a guided tour), and on social media.

- The tendency in two sites to share experiences regarding promotional tasks, participating in tenders, and investing operations.

With the greatest possible projection of the effectiveness of communication, the implementation of the main purpose of this research commenced, which was the identification of features and attributes of tourist sites affecting the degree of inter-organizational trust. Using a variable describing the effectiveness of communication as one of the variables (along with the other variables describing the IMR sites), a multiple regression model was created. The parameters of the created model are described in Table 6. The obtained predictions, in comparison with the observations obtained during interviews, had a large level of linear correlation $\left(r_{x y}=0.915\right)$. The coefficient of determination $\left(R^{2}=0.838\right)$ confirms the good fit of the model.

Table 6. Multiple regression model parameters for the trust variable between any given site of the IMR.

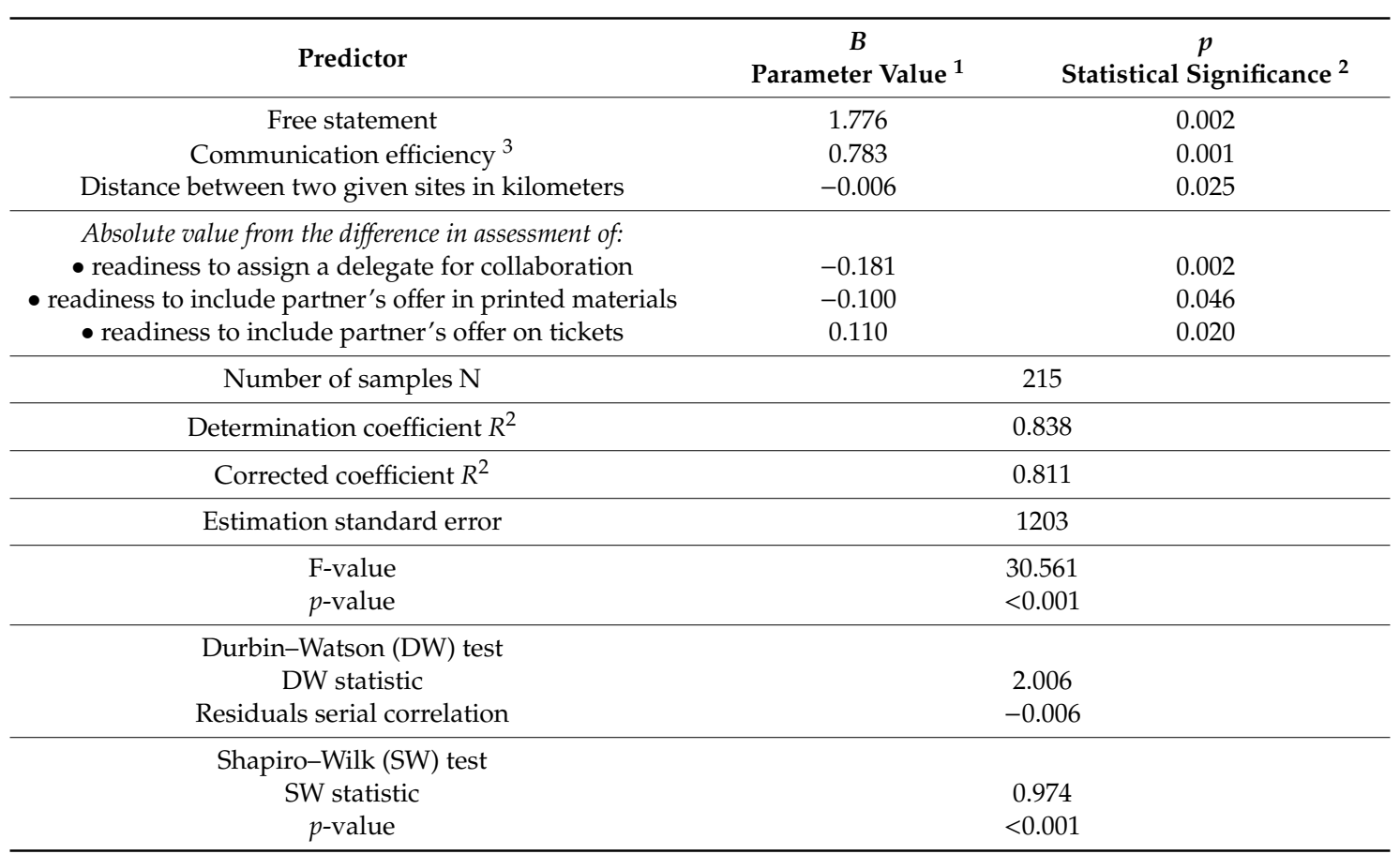

${ }^{1}$ Predictor regression coefficient. ${ }^{2}$ Level of parameter significance. ${ }^{3}$ Estimated using the previously created regression tree. (Source: Authors' research.).

The high $\left(R^{2}=0.838\right.$. $)$ determination coefficient suggests a good match of the model; it allows explaining $83.81 \%$ of all trust variation. Table 7 contains ANOVA results for the created regression model that confirms this ratio. 
Table 7. Analysis of variation (ANOVA).

\begin{tabular}{cccccc}
\hline & Sum & df & Mean & $\boldsymbol{F}$ & $p$ \\
\hline Regression & 1371.092 & 31 & 44.229 & 30.561 & $<0.001$ \\
Residual & 264.843 & 183 & 1.447 & & \\
Total & 1645.935 & & & & \\
\hline
\end{tabular}

Source: Authors' own work

The F-value $(\mathrm{F}=30.561, p<0.001)$ indicates that the model is statistically significant. And the analysis of residuals confirms the correctness of the model. The Durbin-Watson test statistic $(\mathrm{DW}=2.006)$ allows to conclude that there was no autocorrelation between residuals (since residuals serial correlation ratio was negative, the $D W$ value had to be less than the critical value $(D W=2.177)$ in order to rule out negative autocorrelation). The normal distribution of residuals was tested using the Shapiro-Wilk test. The $p$-value $(<0.001)$ did not confirm the normality of distribution, but the SW statistic (0.974) differed from the critical value (0.987) slightly. It can be assumed that the distribution of residuals is close to normal and, according to the literature [39], such an occurrence is acceptable in cases of big enough samples. This was confirmed by the histogram and the graph of residuals normality (these charts are not included due to limited space). In the graph for residual distribution to the predicted values, we noticed that the points are equally scattered and do not concentrate at any specific point. This confirms the homoscedasticity of the random term.

It must be noted that the three coefficients of regression in the created model have a negative value. This applies to the distance between the two sites-the smaller the distance, the larger the degree of inter-organizational trust. Moreover, it should be noted that the coefficient of regression of that variable is relatively small compared to the others. The reason for this is the fact that it was the only variable, considered in the model, which did not relate to the assessments expressed using the scale of 1 to 10, but instead to the distance expressed in kilometers (which, for the IMR sites, could be between 1.1 to $164 \mathrm{~km}$, and on average was $58.74 \pm 48.03 \mathrm{~km}$ ). The remaining two negative regression coefficients concern the difference in the assessment of readiness to appoint delegates for cooperation matters and including information on partner's offer in printed materials. This means that the smaller the divergence in the assessment of two sites, the larger the level of trust between them. Taking into account the previously observed strong dependency between the assessment of the effectiveness of communication and the level of trust, the high level of regression coefficient corresponding to the variable describing communication in the created model was expected.

The obtained model allowed the authors to estimate the degree of inter-organizational trust between any given pair of tourist sites on the IMR. The prediction required the previous identification of the effectiveness of cooperation between each of the studied entities, which was achieved using the C\&RTs method.

\section{Reference to Other Studies}

This paper attempts to explore the relation between industrial heritage tourist venture features and the level of trust between them when they function within one tourist route. Our empirical analysis, which took the IMR as an example, revealed that indeed there is a set of specific features that affects inter-organizational trust between the named sites. Moreover, the features have not only been identified but their influence on the level of trust was expressed quantitatively by a statistical model. It confirms the previously stated linkage and bilateral relation between trust and communication in the literature [20]. In the researched case, this was the most influential trust feature of all. But the efficiency of communication itself emerges from other features, alongside features named in the literature of the subject [19] (i.e., information and experience sharing, readiness to cooperate in various forms and areas). In the researched case, it was also affected by the distance between two sites, their influence on the IMR and their experience on the market (years of activity). The fact that spatial proximity affects the efficiency of communication even within a regional route might seem surprising-especially in the 
age of technological progress, which offers a multitude of possibilities of communication, transgressing physical barriers. The explanation for this might be the nature of a tourist route itself; it is designed for tourists to travel from site to site within a designated path. Therefore, it is in the interest of each site to have a good relation and stay in constant contact with neighboring facilities in order to sustain a good reputation and be recommended to visitors who decide whether to continue exploring the route. The tourist perspective is one of the reasons. The other reason is that neighboring tourist entities are often governed by the same self-government (or they are at least dependent on it) that involves them in local events. Furthermore, it is the institution that is responsible for local legislation and public funding - those decision-making processes affect these facilities and, when well communicated, they can state and represent their interests more effectively.

During the literature review, it was also noted that there are five decisive features (proximity, participation in a network, institutional, relational and knowledge similarity) that affect the willingness to share information and, in the end, also effect level of trust [23]. The conducted research not only confirms this but also shows the degree to which those features affect it in the IMR sites. The most decisive these, as previously stated, is the effectiveness of communication and the features affecting this have already been described above. According to the obtained data, the next features are institutional similarity (in our model, this was mainly expressed by a similar approach to undertaking joint promotional tasks) and spatial distance (the smaller the distance, the higher the trust). The relation between the distance separating two facilities and their level of trust towards each other originates from the same reasons as the dependency between distance and communication efficiency. The gathered data allows concluding that institutional similarities don't affect the level of inter-organizational trust as much as spatial proximity does. The regression model does not show this directly but when one considers the results from trust evaluation in groups of near, similar and furthest sites, it becomes clearer. Both the assessments of trust and communication were the highest within sites that were close together. The second highest notes in those aspects were given in the groups of similar sites, and the lowest ones were in groups of sites that were the furthest apart. This, in juxtaposition with the literature findings, [21-29] means that even if all dimensions of proximity have some effect on inter-organizational trust, in the case of tourist sites that function on a regional route, the geographical and organizational dimensions are the most significant dimensions.

These findings might be useful in the planning of shared activities for such sites (by a government, tourist organization, or a tourist sites association that attempts to unite them) or in the design of cooperation in the form of a route, cluster, regional development programs or an inter-organizational network.

The statistical models presented in this paper can be applied by the IMR administrators, while planning an activity concerning multiple sites or when developing an organizational structure in order to assess the trust between potential partners and to determine whether they possess features that are in favor of high trust. Moreover, in cases when the potential partners are spread far out on the route, the model can be used to determine whether the potential partners possess appropriate features that allow balancing the difference in distance out.

Furthermore, we believe that the presented methodology and approach to measuring trust can be used in other studies that focus on inter-organizational trust. It can be used either by adapting it to the specification of given industry or by building on it in order to develop a more comprehensive model that can be applied to quantify trust between any two organizations. This is particularly important when one realizes that the previous methods and questionnaires focused mainly on the internal perspective of an organization [21] (to measure, i.e., the trust of employees) while studies concerning inter-organizational trust pertained to conceptualization and operationalization [19]. There is still a wide research gap; even if this study contributes to filling it, it is the first step on a long path. 


\section{Conclusions}

The variable regression model describing the level of inter-organizational trust created for the IMR sites is the first attempt at such research. Previous studies that can be found in the literature analyzed trust from a sociological perspective, based on behavioral and cognitive mechanisms. Our study extends the knowledge on how trust is established, especially in tourism. The obtained quantitative data allowed us to identify features of tourist sites that have direct impact on the level of inter-organizational trust between tourist sites. The same data was then used to build a statistical model, that allows one to estimate the level of trust between any pair tourist sites on the IMR. Such a tool can be useful when planning inter-organizational relations or cooperation structures.

The created model is not universal. On other routes, its parameters could be different (due to the difference in the scale of distances between the sites, for instance). However, it allowed identifying features affecting the degree of inter-organizational trust among the studied sites. These were: geographical distance between the sites (the lower the distance, the higher the level of trust), unanimity of views on appointing an employee responsible for cooperation with other sites, the degree of readiness to post promotional materials of partner sites on tickets and printed promotional materials, as well as the effectiveness of communication with other sites. The last feature is the resultant value of other features of the tourist sites. Based on the created model of regression trees, it was identified that it is affected by the difference or similarity in: the years of operation of the sites, the number of tourists visiting the site in a year, the number of employees (higher trust existed for sites with a significant difference in headcount), the difference between these sites, the willingness to create joint events and joint products, the views on networking, the perceived impact of the site on the shaping of the IMR and the level of difficulty in meeting the expectations posed by the IMR, the readiness to share experience (on promotional activities, participation in trade fairs and conducting investments) and post offers of other sites on tickets, in social media and in the content of the narrative of tour guides on the site.

Moreover, when studying the correlation between the assessments of the level of trust and other parameters describing tourist enterprises, it was noted that-to a lesser degree than in the models created by the authors, and yet still statistically significant-there is an impact of the following features on inter-organizational trust (apart from the features mentioned previously): willingness to organize joint meetings and establish permanent electronic communication, as well as willingness to share information on the obtaining of funds for activity.

Predicting the level of trust between tourist sites requires further research on other cases. This would provide an answer to the question of whether there is a set of features of tourist sites that allows estimating the level of trust, regardless of the route on which they are located. The ability to determine the level of trust between tourist sites may be used to develop models of advanced forms of cooperation.

In its further research, the authors plan to create a model of an inter-organizational network of cooperation for the IMR sites. The basis for creating network relations will be the level of inter-organizational trust, estimated by using the methodology described herein.

Author Contributions: A.R.S. developed the methodology, introduction, conclusions, and research, and also prepared the final contents of the article and proofread and revised it. M.N. reviewed the literature in terms of business models and post-industrial enterprises, and conducted research, as well as prepared the characteristics of the Industrial Monuments Route in Poland.

Funding: This research received funding by the National Science Center in Poland.

Acknowledgments: This paper was published as part of the research project 'A business model for health resort enterprises' No. 2017/25/B/HS4/00301, supervised and financed by the National Science Center in Poland and as part of statutory research 13/010/BK_19/0034 at the Silesian University of Technology, Faculty of Organization and Management.

Conflicts of Interest: The authors declare no conflict of interest. The funders had no role in the design of the study; in the collection, analyses, or interpretation of data; in the writing of the manuscript, or in the decision to publish the results. 


\section{References}

1. Bangstad, T.R. Routes of Industrial Heritage: On the Animation of Sedentary Objects. Cult. Unbound: J. Curr. Cult. Res. 2011, 3, 279-294. [CrossRef]

2. Kirshenblatt-Gimblett, B. Destination Culture: Tourism, Museums and Heritage; University of California Press: Berkeley, CA, USA, 1998.

3. Halewood, C.; Hannam, K. Viking heritage tourism: Authenticity and commodification. Ann. Tour. Res. 2001, 3, 565-580. [CrossRef]

4. Xie, F.P. Developing industrial heritage tourism: A case study of the proposed jeep museum in Toledo. Tour. Manag. 2006, 6, 1321-1330. [CrossRef]

5. Bottero, M.; D'Alpaos, C.; Oppio, A. Ranking of Adaptive Reuse Strategies for Abandoned Industrial Heritage in Vulnerable Contexts: A Multiple Criteria Decision Aiding Approach. Sustainability 2019, 11, 785. [CrossRef]

6. Kuščer, K.; Mihalič, T. Residents' Attitudes towards Overtourism from the Perspective of Tourism Impacts and Cooperation-The Case of Ljubljana. Sustainability 2019, 11, 1823. [CrossRef]

7. Chenxi, L.; Zhengyan, C.; Jing, C.; Ning, Z. Brand Revitalization of Heritage Enterprises for Cultural Sustainability in the Digital Era: A Case Study in China. Sustainability 2019, 11, 1769.

8. Wang, R.; Liu, G.; Zhou, J.; Wang, J. Identifying the Critical Stakeholders for the Sustainable Development of Architectural Heritage of Tourism: From the Perspective of China. Sustainability 2019, 11, 1671. [CrossRef]

9. Pop, I.L.; Borza, A.; Buiga, A.; Ighian, D.; Toader, R. Achieving Cultural Sustainability in Museums: A Step Toward Sustainable Development. Sustainability 2019, 11, 970. [CrossRef]

10. Czernek, K. Determinants of cooperation in a tourist region. Ann. Tour. Res. 2013, 40, 83-104. [CrossRef]

11. Weng, L.; He, B.; Liu, L.; Li, C.; Zhang, X. Sustainability Assessment of Cultural Heritage Tourism: Case Study of Pingyao Ancient City in China. Sustainability 2019, 11, 1392. [CrossRef]

12. Kulczyk-Dunowska, A.; Bal-Domańska, B. The National Parks in the COntext of Tourism Function Development in Territorially Linked Minicipalities in Poland. Sustainability 2019, 11, 1996. [CrossRef]

13. Lenart, R. Relational capital for managing the uncertainty of environment. J. Sci. Mil. Acad. Land Forces 2015, $47,58-69$.

14. Edelendos, J.; Klijn, E.H. Trust in complex decision-making networks: A theoretical and empirical explanation. Adm. Soc. 2007, 39, 25-50. [CrossRef]

15. Lewis, J.D.; Weigert, A. Trust as a social reality. Soc. Forces 1985, 63, 967-985. [CrossRef]

16. Fukuyama, F. Trust: The Social Virtues and the Creation of Prosperity; Penguin Putnam; Free Press: New York, NY, USA, 1995.

17. Growiec, K.; Growiec, J. Social capital, trust, and multiple equilibria in economic performance. Macroecon. Dyn. 2014, 18, 282-315. [CrossRef]

18. Wood, D.J.; Gray, B. Toward a comprehensive theory of collaboration. J. Appl. Behav. Sci. 1991, 27, $139-162$. [CrossRef]

19. Seppänen, R.; Blomqvist, K.; Sundqvist, S. Measuring inter-organizational trust-A critical review of the empirical research in 1990-2003. Ind. Mark. Manag. 2007, 36, 249-265. [CrossRef]

20. Laurent, G. Improving the external validity of marketing models: A plea for more qualitative input. Int. J. Res. Mark. 2000, 17, 177-182. [CrossRef]

21. Dalahaye Paine, K. Guidelines for Measuring Trust in Organizations; The Institute for Public Relations, Weimer Hall: Gainesville, FL, USA, 2003.

22. Parise, S.; Henderson, J.C. Knowledge resource exchange in strategic alliances. IBM Syst. J. 2001, 40, 908-924. [CrossRef]

23. Marrocu, E.; Paci, R.; Usai, S. Proximity, networks and knowledge production in Europe. Technol. Forecast. Soc. 2013, 80, 1484-1498. [CrossRef]

24. Boschma, R.A.; Frenken, K. The Spatial Evolution of Innovation Networks: A Proximity Perspective; Utrecht University, Department of Human Geography and Spatial Planning, Group Economic Geography: Utrecht, The Netherlands, 2009.

25. Czakon, W. Hipoteza bliskości. Przegląd Organ. 2010, 9, 16-20.

26. Boschma, R.A. Proximity and Innovation: A Critical Assessment. Reg. Stud. 2005, 39, 61-74. [CrossRef] 
27. Knoben, J.; Oerlemons, L.A.G. Proximity and Inter-organizational Collaboration: A Literature Review. Int. J. Manag. Rev. 2006, 8, 71-89. [CrossRef]

28. Klimas, P.; Twaróg, S. Inter-organizational Proximity in the Context of Logistics-Research Challenges. LogForum 2015, 11, 109-117. [CrossRef]

29. Huggins, R.; Johnston, A. Knowledge flow and inter-firm networks: The influence of network resources, spatial proximity and firm size. Entrep. Region. Dev. 2010, 22, 457-484. [CrossRef]

30. Ghobadi, S.; D'Ambra, J. Coopetitive relationships in cross-functional software development teams: How to model a measure? J. Syst. Softw. 2012, 85, 1096-1104. [CrossRef]

31. Naramski, M.; Szromek, A. Configuring a Trust-based Inter-organizational Cooperation Network for Post-industrial Tourist Organizations on a Tourist Route. Sustainability 2019, 11, 3542. [CrossRef]

32. Szromek, A.R.; Herman, K. A Business Creation in Post-Industrial Tourism Objects: Case of the Industrial Monuments Route. Sustainability 2019, 11, 1451. [CrossRef]

33. Wilkinson, L. Classification and Regression Trees, Systat; Routledge: Abingdon, UK, 2004.

34. Yohannes, Y.; Hoddinott, J. Classification and Regresion Trees: An Indtroduction; International Food Policy Research Institute: Washington, DC, USA, 1999.

35. Cozzio, C.; Bullini Orlandi, L.; Zardini, A. Food Sustainability as a Strategic Value Driver in the Hotel Industry. Sustainability 2018, 10, 3404. [CrossRef]

36. Hair, J.F.; Hult, G.T.M.; Ringle, C.M.; Sarstedt, M. A Primer on Partial Least Squares Structural Equation Modeling; Sage: Thousand Oaks, CA, USA, 2014.

37. Google Maps Service. Available online: https://www.google.pl/maps (accessed on 7 June 2017).

38. Website of the Route. Available online: http://www.zabytkitechniki.pl (accessed on 7 June 2017).

39. Stanisz, A. Przystępny Kurs Statystyki; StarSoft: Kraków, Poland, 2000.

(C) 2019 by the authors. Licensee MDPI, Basel, Switzerland. This article is an open access article distributed under the terms and conditions of the Creative Commons Attribution (CC BY) license (http://creativecommons.org/licenses/by/4.0/). 